\title{
Новые материалы для фотоэлектроники на основе двумерных наноструктур
}

\author{
В.П. Пономаренко, В.С. Попов, Е.Л.Чепурнов \\ ГНЦ РФ АО «НПО «Орион», Москва, 111538, Косинскал, 9 \\ тел.: +7 (499) 375-05-50, факс: +7 (499) 373-68-62, эл. почта: orion@orion-ir.ru
}

DOI 10.34077/RCSP2019-17

В последние несколько десятилетий основная часть практически важных разработок в области приёмников инфракрасного излучения фокусировалась на улучшения архитектуры фотоприёмных устройств и поиске новых подходов к обработке сигналов, в части же химии чувствительных материалов наибольшее внимание уделялось оптимизации уже известных составов и соединений. Работы по улучшению фотоприемников во многом ограничиваются физическими свойствами, накладываемыми уже используемыми широко известными чувствительными материалами. Поиск и развитие новых фоточувствительных материалов открывает ранее неиспользованное пространство для развития фотосенсорики. Однако, с точки зрения промышленного внедрения переход на новую компонентную базу и смена чувствительных материалов является наиболее затратным этапом улучшения технологии производства, так как требует значительных средств на смену оборудования и времени на отладку технологии, следовательно, целесообразность таких изменений должна быть вызвана значимыми преимуществами новых материалов.

В настоящее время наибольшее внимание исследователей привлечено изучению возможностей наноструктурирования материалов и использованию 0D, 1D и 2D наноматериалов в качестве новых фотосенсорных материалов [1]. Значительные результаты в последние несколько лет достигнуты в исследовании 2D наноструктурированных материалов, таких как графен, однослойные дихалькогениды переходных металлов и фосфорен (материал на основе черного фосфора включающий несколько атомных слоев) [2]. Наиболее изученными из двумерных материалов являются графен и однослойные дихалькогениды переходных металлов, однако значительные успехи уже достигнуты и для материалов на основе других двумерных наноструктур, в частности, черного фосфора, благодаря высокой подвижности носителей заряда и широким возможностям управления шириной запрещенной зоны, а также анизотропии свойств $[3,4]$. Однако кроме графена, дихалькогенидов переходных металлов и черного фосфора на сегодняшний день известно уже несколько сотен двумерных материалов, в том числе их комбинации в виде Ван дер Ваальсовых гетеростурктур, также перспективных для создания фотодетекторов [5-8]. Согласно расчётам и уже опубликованным в литературе практическим результатам двумерные фоточувствительные материалы открывают возможности создания неохлаждаемых фотоприёмных устройств на средний и дальний ИК диапазон, а также устройств с перестраиваемой спектральной чувствительностью [9-10].

Рассмотренное в докладе многообразие материалов и широкие возможности их комбинирования в гетероструктурах ставят вопрос выстраивания методологии отбора материалов, в том числе с использованием квантово-химических методов расчёта с целью обоснования подхода для создания фоточувствительных элементов для нового поколения фотоприёмных устройств.

\section{Лumepamypa}

[1] F. Xia et al. // Nature Photonics. 2014. Vol. 8, № 12. P. 899-907.

[2] Chao Xie, Chunhin Mak, Xiaoming Tao, and Feng Yanю Advanced Funct. Mater. 2017. Vol. 27, P. 1603886

[3] F. Xia, H. Wang, Y. Jia // Nature Communication. 2014. Vol. 5, P. 4458.

[4] N. Youngblood et al. // Nature Photonics. 2015. Vol. 9, P. 247-252.

[5] A. K. Geim, I. V. Grigorieva // Nature. 2013. Vol. 4 9 9, P. 419-425.

[6] D. Jariwala, T. J. Marks, M.C. Hersam // Nature Materials, 2016. Vol. 16, P.170-181.

[7] D.K. Bediako et al. // Nature. 2018. Vol. 558, P. 425-429.

[8] K. S. Novoselov, A. Mishchenko, A. Carvalho, A. H. Castro Neto // Science. 2016. Vol. 353, Issue 6298, P. aac9439.

[9] M. Long et al. // Science advances. 2017, Vol. 3, P. e1700589.

[10] S. Yuan et al. / Nano Letteres, 2018. Vol. 18, P.3172-3179. 